\title{
CANSANCIO EMOCIONAL EN MÉDICOS ANESTESIÓLOGOS, COMO FACTOR ASOCIADO AL SÍNDROME DE BURNOUT POR EL COVID-19
}

\author{
Neuro Fernando Galbán Padrón** \\ https://orcid.org/0000-0002-8978-5347 \\ Nidia Devonish Nava*** \\ https://orcid.org/0000-0002-4585-5374 \\ Mery Guerra Velásquez**** \\ https://orcid.org/0000-0002-2471-8020 \\ Cesar José Marín Marcano***** \\ https://orcid.org/0000-0002-2340-4548
}

RECIBIDO: Febrero 2021 / ACEPTADO: Abril 2021 / PUBLICADO: Mayo 2021

\begin{abstract}
Como citar: Galbán Padrón, Neuro; Devonish Nava, Nidia; Guerra Velásquez, Mery; Marín Marcano, Cesar. (2021). Cansancio emocional en médicos anestesiólogos, como factor asociado al síndrome de Burnout por el Covid-19. Telos: revista de Estudios Interdisciplinarios en Ciencias Sociales, 23 (2), Venezuela. (Pp.450-465).

DOI: www.doi.org/10.36390/telos232.15
\end{abstract}

\section{RESUMEN}

Las exigencias laborales muchas veces generan en el individuo síntomas que van desde la irritabilidad a la depresión, acompañados por agotamiento físico y mental, representando éstos los primeros síntomas del síndrome de Burnout (SB) o estrés laboral crónico. Entre las circunstancias que deben enfrentar los anestesiólogos durante su desempeño, destacan sus largas y delicadas jornadas laborales, a la cual hoy se le suma la exigencia de las extremas medidas de bioseguridad que deben tener producto del Covid-19 y del temor al contagio durante sus operaciones, las cuales aumentan sus niveles de estrés e impotencia laboral. En este artículo bajo una metodología descriptiva, documental, se describirá el cansancio emocional en médicos anestesiólogos como factor asociado al estrés laboral crónico ó síndrome de Burnout por el Covid-19, en base a los fundamentos del origen del término Burnout introducido por Freudenberger en 1974 y las investigaciones de Maslach y Jackson desde el año 1982 hasta resultados de actuales investigaciones publicadas en revistas arbitradas de alto impacto sobre el tema estudiado, tales como las de Arayago Iriarte, et al.,

\footnotetext{
** Médico Cirujano. Especialista en Anestesiología, Magister Scientiarium en Gerencia Pública. Cursando estudios de Doctorado en Ciencia Medicas, Universidad del Zulia - Maracaibo; Correo electrónico: neurogalban@gmail.com

*** Médica Cirujana, Especialista en Anestesiología, Doctora en Ciencia Médicas, Directora de Postgrado de anestesiología de la Universidad del Zulia, Venezuela. Correo electrónico: nidia.devonish@gmail.com

${ }^{* * * * *}$ Médica Cirujana. Especialista en Ginecología y Obstetricia., Especialista en Metodología de la investigación, Doctora en Ciencia Médicas. Correo electrónico: merygv127@yahoo.es

****** Médico Cirujano. Especialista en Psiquiatría, Doctor en Ciencia Médicas. Director del Departamento de Psiquiatría de la Facultad de Medicina de la Universidad del Zulia. Correo electrónico: cesarmarinm2000@gmail.com
} 
(2016), Rodríguez Paipilla, et al., (2011), Tobie-Gutierrez y Nava-López (2012), entre otros. Concluyendo que el cansancio emocional (CE), constituye un factor clave para la prevalencia del síndrome de Burnout (SB), manifestado a través de la pérdida progresiva de la energía, el desgaste físico, mental y cansancio; causado por la presencia continua de estos signos, sin ser diagnosticados ni tratados eficientemente.

Palabras clave: Burnout, cansancio emocional, médicos anestesiólogos, Pandemia Covid-19.

\title{
Emotional fatigue in anesthesiologists, as a factor associated with Burnout syndrome due to Covid-19
}

\begin{abstract}
Work demands often generate symptoms ranging from irritability to depression, accompanied by physical and mental exhaustion, representing these the first symptoms of Burnout syndrome (BS) or chronic work stress. Among the circumstances that anesthesiologists must face during their performance, their long and delicate working hours stand out, to which today is added the demand for extreme biosafety measures that they must have as a result of Covid-19 and the fear of contagion during their operations, which increase their levels of stress and job helplessness. In this article, under a descriptive, documentary methodology, emotional fatigue in anesthesiologists will be described as a factor associated with chronic work stress or Burnout syndrome due to Covid-19, based on the foundations of the origin of the term Burnout introduced by Freudenberger in 1974 and Maslach and Jackson's research from 1982 to the results of current research published in high-impact peer-reviewed journals on the subject studied, such as those of Arayago Iriarte, et al., (2016), Rodríguez Paipilla, et al., (2011), TobieGutierrez and Nava-López (2012), among others. Concluding that emotional exhaustion (CE) constitutes a key factor for the prevalence of Burnout syndrome (SB), manifested through the progressive loss of energy, physical and mental wear and tear; caused by the continuous presence of these signs, without being diagnosed or treated efficiently.
\end{abstract}

Keywords: Burnout, emotional fatigue, anesthesiologists, Covid-19 pandemic.

\section{Introducción}

A partir del año 1977, se da a conocer el síndrome Burnout, en la convención de la Asociación Americana de Psicólogos, con la exposición de Maslach, donde fue definido como el desgaste profesional de personas que trabajan en diversos sectores de servicios humanos (Martínez Pérez, 2010). En la actualidad y desde hace muchas décadas, el estrés se ha convertido en un grave problema de salud pública; específicamente el denominado estrés laboral crónico, el cual constituye una de las causas de la baja productividad en los trabajadores, independientemente de la organización o empresa donde se encuentren; al respecto, la Organización Mundial de la Salud (OMS, 2004), confirma que el estrés laboral, causa daños tanto a nivel físico como psicológico o mental, en el individuo que lo padece.

Por su parte, Parra Contreras (2020), menciona que a raíz del Covid-19 y la situación de pandemia que se generó en la humanidad a nivel mundial, marcó el inicio de grandes transformaciones, pues la sociedad se dio cuenta que no podía ejercer control sobre 
Cansancio emocional en médicos anestesiólogos, como factor asociado al síndrome de Burnout por el Covid-19

determinadas variables y circunstancias, tampoco estaba preparada para afrontar la complejidad de las situaciones que se vienen presentando, teniendo que ir improvisando en muchos casos para poder adaptarse a los nuevos cambios o la nueva normalidad que se está viviendo.

En ese sentido, existe un número de signos y síntomas que se reflejan en comportamientos y conductas que denotan la presencia del cansancio emocional, observándose cierto nivel de desgaste mental o físico; estos síntomas se presentan en algunos grupos de profesionales tales como los médicos, los docentes o cualquier otra profesión u oficio, en cuyo desenvolvimiento el individuo se ve sometido a altos niveles de presión y exigencia, tanto mental, psicológica, como física. Por lo cual, Arayago Iriarte, et al., (2016), construyeron un instrumento para medir los factores que inciden para la prevalencia del estrés laboral crónico, o como se le ha denominado en inglés, Síndrome de Burnout (SB); este se caracteriza por tres factores principales: El primero es el agotamiento o cansancio emocional (CE); el segundo es la despersonalización (DP) y tercero la baja realización personal (RP).

De acuerdo a lo antes descrito, entre los profesionales donde se presenta con mayor incidencia éste síndrome, están los anestesiólogos, especialidad que por su naturaleza, exige extensas jornadas laborales; siendo la labor del anestesiólogo, el cuidado e intervención de los pacientes antes, durante y después de un acto quirúrgico, por lo cual los médicos que la practican están sometidos constantemente a altos niveles de estrés, que en el tiempo se va acumulando dentro del organismo convirtiéndose en estrés laboral crónico o SB, afectando su desempeño y rendimiento, con alto riesgo para la salud (Calabrese, 2006).

Aunado a esto, en el año 2019 surge un nuevo elemento dentro de este entorno laboral, referido a la presencia del virus Covid-19 a nivel mundial, ocasionando una situación de pandemia, donde como lo plantean Sacrístan y Millán (2020), muchos profesionales sanitarios se enfrentan e ella en unas condiciones subóptimas y se han convertido en uno de los colectivos más vulnerables, trabajan día a día infatigablemente durante larguísimas jornadas y cada día llegan a sus casas con sensación de agotamiento, irritación e impotencia.

De lo anterior se percibe que, al ejercer la profesión del anestesiólogo bajo condiciones no reguladas, discordantes con las políticas o normas establecidas, induce un alto grado de estrés, con consecuencias sobre la salud integral, el plano familiar y personal, debido al alto precio que se debe pagar por mantener un estatus a nivel profesional, prestigio y reconocimiento; requiriéndose un esfuerzo adicional realizar estudios especializados, aquí se habla de la formación, capacitación continua para elevar el nivel de conocimiento y actualización científica y técnica, para lo cual, el tiempo del que se dispone es insuficiente (Arayago Iriarte, et al., 2016).

Tomando en cuenta lo anterior, en este estudio se profundiza sobre el factor número uno referido a la presencia de estrés laboral crónico o SB, como lo indican, Arayago Iriarte, et al. (2016), o como lo definen Maslach y Jackson (1982), el cansancio emocional (CE), caracterizado por la pérdida progresiva de la energía, desgaste y cansancio. Para lo cual, planteó como objetivo: describir el cansancio emocional en médicos anestesiólogos como factor asociado al estrés laboral crónico ó síndrome de Burnout por el Covid-19, bajo una metodología descriptiva, considerando los estudios referidos a los anestesiólogos y su ejercicio profesional durante el Covid-19. 
Para lo cual se iniciará con un abordaje conceptual sobre lo que es la anestesiología y los riesgos que implica su ejercicio profesional, bajo los fundamentos de Rodríguez Paipilla, et al (2011), OMS (2004) y Torres Montes de Oca; et al. (2020); seguido de la descripción del cansancio emocional como respuesta al estrés laboral, los métodos que se pueden utilizar para su prevención en correspondencia con los autores Castillo Ramírez (2000), Martínez Pérez (2010), Maslach y Jackson (1982); Zelaya Hurtado (2016), Tobie-Gutierrez y NavaLópez (2012).

Finalmente, se presentó el abordaje contextual, basado en los artículos de Monsalve (2020), Vasco Ramírez (2020), Calabrese (2020); Cordero Escobar (2020) y INFOSALUS (2021); publicados en revistas de impacto que muestran lo que ha sido la profesión del anestesiólogo durante la presencia del covid-19 y la nueva normalidad originada por la situación de pandemia que se vive mundialmente en los años antes mencionados.

\section{La anestesiología: una labor de riesgo mental para el profesional de salud.}

En la práctica de la anestesiología, el personal médico se ve sometido a una alta carga de ansiedad, presión, exigencias, tanto por la responsabilidad que en lo personal y profesional representa su labor, como por el cuidado y preservación de la vida del paciente además de las demandas de parte de la institución donde laboran; aunado a una serie de situaciones y particularidades relacionadas con el prestigio, la calidad humana y de atención, el conocimiento y la experiencia; que se supone debe poseer como rasgos, este profesional médico.

A las circunstancias antes descritas se le debe sumar ahora la aparición del virus Covid-19 que genera aún más incertidumbre, exigencias y riesgo laboral para los anestesiólogos, aumentando sus niveles de estrés dentro del entorno laboral, al tener que asumir ciertos riesgos de contagio al presentarse al centro de atención médica donde labora, considerando que el SARS-Cov 2 tiene una rápida propagación y sus posibilidades de contagio son elevadas en el personal médico que debe ejercer las funciones referidas a garantizar una vía aérea permeable y segura. Por lo cual, se requiere de un entrenamiento y actualización continua para todo el que permanezca estrechamente vinculado a estos pacientes (Torres Montes de Oca; et al., 2020), con las medidas de bioseguridad respectivas a fin de prevenir al máximo posible sus probabilidades de contagio.

Un análisis necesario en cuanto a la presencia o no del cansancio emocional (CE), está ligado a la existencia de aspectos que influyen negativa o positivamente para ello; los primeros contribuyen a que este factor se haga presente y sea recurrente, y los segundos (aspectos positivos) evitan su aparición, promoviendo un mayor control y equilibrio en la salud mental de los trabajadores (Rodríguez Paipilla, et al, 2011).

En tal sentido, los aspectos negativos afectan la salud en general, por ejemplo al crearse desequilibrios entre las exigencias y presiones a las que se enfrenta el individuo, que rebasan sus capacidades, habilidades, destrezas y conocimientos, OMS (2004), y los aspectos positivos que lo benefician, porque en la medida que el entorno laboral sea saludable, las exigencias se corresponden con las capacidades y recursos del individuo para afrontarlo; creándose una sensación de control sobre el entorno y la actividad que se desarrolla; además de esto, si se cuenta con apoyo psicológico, emocional y afectivo de parte tanto de la empresa 
Cansancio emocional en médicos anestesiólogos, como factor asociado al síndrome de Burnout por el Covid-19

como en la vida personal; podría decirse que existe un estado de bienestar físico, mental o de buena salud (Rodríguez Paipilla, et al., 2011).

Todo lo anterior depende de una evaluación permanente de los riesgos para la salud, el suministro de información y capacitación adecuada en materia de salud y la disponibilidad de estructura y prácticas institucionales de apoyo que promuevan la salud (OMS, 2004).

Partiendo de la descripción y definición del Síndrome de Burnout, de Maslach y Jackson (1982), el síndrome de Burnout, es una manifestación comportamental por estrés laboral crónico, y lo significan como un síndrome tridimensional caracterizado por cansancio emocional (CE), despersonalización (DP) en el trato con clientes y usuarios, y dificultad para el logro/realización personal (RP) ; siendo la mayor manifestación de estar padeciendo estrés crónico, el cansancio o agotamiento emocional (Martínez Pérez, 2010).

\section{Cansancio emocional en respuesta al estrés laboral del anestesiólogo}

El cansancio emocional (CE) es el núcleo del síndrome de Burnout, el cual es producido por una sobrecarga emocional constante (Martínez Pérez, 2010); también se define como: cansancio mental, acompañado de fatiga física y un estado del cual la persona cree no poder salir o recuperarse, (Castillo Ramírez, 2000). Fue definido por Maslach y Jackson (1982), como uno de los elementos del síndrome de Burnout, caracterizado por la pérdida progresiva de energía, desgaste generalizado, físico o mental; agotamiento, cansancio o fatiga, entre otros; pudiéndose agregar, la falta de ánimo hacia las tareas o labores que se realizan en el trabajo.

El Burnout incluye varios síntomas que pueden ser perceptibles, debido a cambios muy evidentes en el individuo; el CE es uno de los principales síntomas a tomar en consideración cuando se presume el padecimiento de estrés laboral crónico, en donde:

....la persona se implica en exceso en sus actividades, labores o roles, ya que intenta atender demasiadas exigencias inaplazables, resultando al final que se verá desbordada por los requerimientos que le imponen los demás. Es un proceso psicológico donde el individuo se siente "vacío" y le falta energía para afrontar un nuevo día, por ejemplo; por otra parte, la persona no se siente capaz de dar nada de sí a los demás, intentando reducir el contacto con la gente, y lo hace sólo lo necesario para realizar su trabajo; esto ocasiona que el trabajador vea a otros de forma negativa, ignorándoles, lo que llevará al profesional a ofrecer solo cuidados técnicos, olvidándose del aspecto humano de la profesión, (Zelaya Hurtado, 2016; p.2).

El cansancio emocional se define como la "pérdida progresiva de energía, el desgaste, agotamiento físico y psicológico, la fatiga, condiciones del ser humano que le dan la sensación de estar hecho polvo y de tener demasiadas exigencias a partir del contacto con otras personas" (Lledó Carreres; et al., 2014; p.162). La persona que presenta síntomas de cansancio emocional no está en condiciones de responder a las exigencias laborales y generalmente se encuentra en estado de irritabilidad y depresión aunado al sentimiento de querer abarcar demasiadas cosas pero sus recursos emocionales y físicos están agotados, siendo está la característica principal del síndrome de Burnout. 
Durante los últimos años, se ha considerado el síndrome de Burnout como un factor asociado al estrés laboral, reflejándose falta de interés, la disminución e incluso pérdida de su satisfacción laboral en los profesionales (González Ramírez y Landero Hernández, 2007). "Dentro de la tendencia a aplicar el Burnout sólo a profesiones asistenciales, Maslach y Schaufeli (1993) intentaron una ampliación del concepto aceptando diversas definiciones en función de algunas características similares, de las que destacan: 1. Predominan más los síntomas mentales o conductuales que los físicos. Entre los síntomas disfóricos se señalan, el cansancio mental o emocional, fatiga y depresión; siendo el principal el Cansancio Emocional. 2. Los síntomas se manifiestan en personas que no sufrían ninguna Psicopatología anteriormente. 3. Se lo clasifica como un síndrome clínico-laboral. 4. Se desencadena por una inadecuada adaptación al trabajo, que conlleva a una disminución del rendimiento laboral junto a la sensación de baja autoestima (Martínez Pérez, 2010; p.45).

Por lo tanto, se estima que el cansancio emocional (CE) es uno de los tres síntomas determinantes del síndrome de Burnout, o más comúnmente llamado estrés laboral crónico; según las investigaciones realizadas por Maslach y Jackson, quienes al construir el cuestionario "Maslach Burnout Inventory" (MBI) definen el CE como: "sensación de no poder dar más de sí mismo a nivel afectivo, creando una situación de agotamiento de energía o recursos emocionales debido al contacto diario y continuo con personas en problemas" (SolísCondor, et, al, 2017; p.271).

El individuo con cansancio emocional, se ve afectado por problemas emocionales, ansiedad, sentimientos de impotencia, irritabilidad, conducta agresiva, además que también afecta a la institución donde labora, produciéndose baja o mala calidad asistencial y de atención a los pacientes y demás personal con los que se relaciona (Solís-Condor, et al., 2017).

Por otra parte, el cansancio emocional (CE) es el aspecto clave en el Modelo Procesual planteado por Leiter, el cual parte del Modelo secuencial de Leiter y Maslach (1988), citado por Martínez Pérez (2010), donde indican que la aparición del Burnout, empieza por la existencia del desequilibrio entre las demandas de la organización y los recursos del individuo para atender esas demandas; produciéndole cansancio emocional.

Ahora bien, teniendo ya el conocimiento por medio de las investigaciones realizadas sobre este aspecto, uno de los sectores profesionales más vulnerables para el padecimiento del estrés laboral es el de los trabajadores de la salud (médicos y enfermeras). Al respecto, el estar constantemente sometidos a situaciones que producen una alta carga emocional, cuya persistencia en el tiempo conlleva a un cansancio emocional recurrente, ocasiona en muchas situaciones que los médicos anestesiólogos posean una vulnerabilidad mayor en cuanto a padecer este síntoma, ya que por sus características y naturaleza, la especialidad es altamente demandante y exigente tanto física, como psicológicamente. Existiendo mucha presión y presentándose el individuo que la manifiesta: pérdida de energía continua, desgaste físico, mental, cansancio general, los cuales vienen a ser los tres signos más representativos del cansancio emocional (Arayago Iriarte, et al., 2016).

El cansancio emocional es un síntoma complejo en sí mismo, que aparte de presumirse como manifestación de "estrés laboral", constituye una verdadera preocupación, en 
Cansancio emocional en médicos anestesiólogos, como factor asociado al síndrome de Burnout por el Covid-19

tanto que proviene directamente de las emociones del individuo, que se encuentra en un estado emocional y psicológico en franco deterioro o desequilibrio, que alteran el equilibrio emocional de las personas (Clínica Galatea, 2018). Como consecuencia se empieza a observar: incumplimiento de sus funciones, ausentismo laboral, disminución del grado de satisfacción profesional y laboral y pérdida de la productividad (Arayago Iriarte, et al., 2016).

Es importante destacar, que la presencia de otros factores asociados, como la motivación, problemas de personalidad o psicosociales (por ejemplo, no contar con una red social 0 relaciones interpersonales adecuadas) suelen tener un peso importante en la subsiguiente aparición del síndrome de desgaste emocional (Secín Diep y Rodríguez Weber, 2016).

En relación con lo anterior, el riesgo de que el personal médico de cualquier clínica u hospital público, observe cansancio emocional (CE), está asociado básicamente a factores organizacionales, pero más directamente con el tipo de actividad que se realiza y la cantidad de horas que se le dedica. En un estudio realizado por Hutter, citado por Tobie-Gutierrez y Nava-López, (2012); se demostró que la reducción de la jornada laboral de los residentes de cirugía a 80 horas semanales disminuía significativamente el cansancio emocional. Pudiendo ser más significativos para la presencia de este síntoma, los aspectos sobre el clima y la cultura del propio ámbito de trabajo, en contraposición con los aspectos personales, psicológicos o de conducta de los individuos (Martinetti y Paladino, 2005).

Algunas de las causas del estrés laboral en este grupo específico de especialistas, se debe a las decisiones que en un momento dado tienen que tomar, entre la familia y vida personal por un lado y la profesión por otro lado; además comentan que la presión asistencial en el lugar de trabajo, la exigencia propia de la labor médica, conlleva a una descapitalización profesional, ocasionada por la presión y la burocratización de la labor; que les impide aplicar con plenitud lo aprendido, aunado al no poder tener la oportunidad de formarse y capacitarse por falta de tiempo, ya que llevarlo a cabo es prácticamente una extensión de la jornada laboral, todo ello en detrimento del tiempo libre o de descanso (Martinetti y Paladino, 2005).

Si a lo anterior se le agrega la actual presencia del virus Covid-19 y todos los riesgos que el mismo involucra, más hacia el sector médico que se ve directamente relacionado con personas que lo puedan padecer dentro de sus instituciones de servicio asistencial donde laboran, donde pueden terminar siendo contagiados contacto cercano o quizás llegar a ser un portador asintomático del virus y con esto contagiar a sus familiares cercanos, originando así otra situación de presión, angustia y más exigencias en términos de cuidado personal al dirigirse a su sitio de trabajo que aumenta los síntomas para padecer cansancio emocional.

En líneas generales se ha podido observar en la literatura consultada, los aspectos 0 signos que caracterizan el CE en los anestesiólogos, pueden estar relacionados con la presencia de estrés crónico o Burnout, siendo esto evidenciado si se toma en cuenta el hecho, que los profesionales de la anestesiología son el grupo de personal médico de hombres y mujeres que conviven durante largos períodos de tiempo, prácticamente confinados en ambientes cerrados o restringidos y enfrentando diversas situaciones de tensión psicológica y mental (condiciones propicias para el contagio de Covid-19); además de la exigencia física a la que deben someter su cuerpo; están alejados del ritmo normal de vida del ambiente 
exterior, y con frecuencia enfrentando todo tipo de situaciones legales que amenazan su integridad profesional (Tobie-Gutierrez y Nava-López, 2012).

La descripción de una situación donde se presuma el SB en los médicos anestesiólogos, ah de observarse básicamente por medio del cansancio emocional ( $\mathrm{CE}=$ pérdida de energía continua, desgaste físico y mental; y cansancio en general), por ser el aspecto que se percibe con más frecuencia, pero uno de los más leves, y que se presentan en una fase inicial de la crisis por estrés laboral. Los signos característicos del CE y que se pudieran detectar en la práctica diaria de los anestesiólogos; se encuentran registrados en el instrumento (MBI) que evalúa el Síndrome de Burnout elaborado por Maslach de 22 ítems, entre los cuales 9 son los que determinan CE; como se puede observar en el cuadro 1.

\section{Cuadro 1. Signos del Cansancio Emocional}

Signos de Cansancio Emocional (CE): según Maslach (1976), citado por Secín Diep y Rodríguez Weber (2016), se considera que al existir niveles elevados de cansancio emocional, existe síndrome de Burnout

\begin{tabular}{|c|c|c|}
\hline $\begin{array}{c}\text { Aspectos } \\
\text { determinantes del } \\
\text { Cansancio emocional } \\
\text { (Maslach y Jackson, } \\
\text { 1982) }\end{array}$ & $\begin{array}{l}\text { Indicadores del Cansancio emocional } \\
\text { (CE) según el MBI : Cuestionario auto } \\
\text { administrado, constituido por } 22 \text { items } \\
\text { sobre los sentimientos y actitudes del } \\
\text { profesional en su trabajo y hacia los } \\
\text { pacientes, (Martinetti y Paladino, 2005) }\end{array}$ & $\begin{array}{l}\text { Predisposición según la } \\
\text { Personalidad } \\
\text { Pudiera existir predisposición a } \\
\text { manifestar este síntoma (CE) en } \\
\text { respuesta al estrés de acuerdo al tipo } \\
\text { de personalidad que se tiene. } \\
\text { (Martinetti y Paladino, 2005) }\end{array}$ \\
\hline $\begin{array}{l}\text { Son tres básicamente: } \\
\text {-Pérdida progresiva de } \\
\text { la energía } \\
\text {-Desgaste físico y } \\
\text { mental } \\
\text {-Cansancio }\end{array}$ & $\begin{array}{l}\text { Esta es la Sub escala de indicadores } \\
\text { del Cansancio Emocional (CE), que } \\
\text { comprende las siguientes } 9 \\
\text { preguntas, que miden el cansancio } \\
\text { emocional, por exigencias en el } \\
\text { trabajo, (Martinetti y Paladino, 2005) } \\
\text { 1. Me siento emocionalmente agotado } \\
\text { 2. mor mi trabajo } \\
\text { 2. Me siento cansado al final de la } \\
\text { 3. jornada de trabajo } \\
\text { 4. Me siento fatigado cuando me levanto } \\
\text { Trabajar todo el día con mucha gente } \\
\text { 5. Me un esfuerzo } \\
\text { 6. Me siento usado en mi trabajo } \\
\text { 7. Creo que estoy trabajando } \\
\text { 8. Trabajar directamente con personas } \\
\text { 8. Trabado } \\
\text { 9. Me siento acabado }\end{array}$ & $\begin{array}{l}\text { Conocerse y saber en qué } \\
\text { circunstancias, situaciones } \\
\text { momentos se es más vulnerables y } \\
\text { susceptibles, es una estrategia para } \\
\text { manejarlo psicológicamente sabiendo } \\
\text { que la incidencia es mayor cuando: } \\
\text {-Se tiene dificultad para manejar } \\
\text { grupos } \\
\text {-Se perciben débiles, impacientes, } \\
\text { intolerantes, hostiles } \\
\text {-Se tiene baja tolerancia a la } \\
\text { frustración } \\
\text {-No pueden controlar sus impulsos } \\
\text {-Se tiene poca confianza en sí } \\
\text { mismos } \\
\text {-Tienen dificultad para expresar } \\
\text { sentimientos y dar afecto } \\
\text {-Cando tener autoestima o buena } \\
\text { autoimagen depende de las demás } \\
\text { personas } \\
\text {-Cuando se tiene necesidad de } \\
\text { figurar o tener éxito } \\
\text { (Martinetti y Paladino, 2005) }\end{array}$ \\
\hline
\end{tabular}

Fuente: Elaboración propia. En base a: Martinetti y Paladino (2005), Secín Diep y Rodríguez Weber (2016).

A modo de reflexión, el cansancio emocional, que pueden llegar a padecer los médicos anestesiólogos en cualquier época de su ejercicio profesional, no debe subestimarse 
Cansancio emocional en médicos anestesiólogos, como factor asociado al síndrome de Burnout por el Covid-19

puesto que las consecuencias pueden llegar a ser complicadas, dificultando tener una calidad de vida laboral más sosegada, inclusive en algunos casos más graves se manifiestan con el abuso de psicofármacos, absentismo, abuso de alcohol y drogas, entre otros síntomas, lo que compromete la salud en diferentes grados y con variedad de padecimientos, causando un caos impredecible en la persona, tanto emocional, psicológico o mental y físico.

\section{¿La Prevención del cansancio emocional, es posible?; medidas y recomendaciones.}

Como ya se ha mencionado, el cansancio emocional (CE), es un factor clave para la determinación del síndrome de Burnout (SB), aún sin la manifestación de los otros dos factores (la despersonalización y la baja realización personal); la prevención en una primera fase, consistiría en identificar los signos sin subestimar lo leves que estos pudieran ser. Se conoce desde hace décadas sobre la existencia de este síndrome; sin embargo, en la actualidad se sabe que puede llegar a convertirse en una enfermedad grave producto del deterioro del sistema inmunológico; con mayor incidencia en el gremio de los profesionales de la salud, dado la emergencia a nivel de salud latente por el Covid-19, convirtiendo a los anestesiólogos en uno de los grupos más vulnerables de contagio y estrés laboral.

De acuerdo a esto, la anestesiología es un área sumamente exigente para los que la practican, donde, resulta importante identificar y afrontar el inicio de una crisis en el aspecto emocional principalmente; sin descartar que en los anestesiólogos es normal tener una cantidad de estrés, como una particularidad de una situación laboral condicionada bajo fuertes elementos ligados a los exigentes marcos legales de cada contexto (Tobie-Gutierrez y NavaLópez, 2012).

Ahora bien, en respuesta al título y pregunta de este apartado: se puede afirmar que sí, si es posible prevenirlo, equilibrando o estableciendo un balance entre el ritmo de vida laboral o profesional y el que lleva en su vida personal. Siendo de vital importancia que en lo personal, cada médico, cada especialista, sea anestesiólogo o de cualquier otra área, busquen un diagnóstico precoz, sepan qué hacer y cómo afrontar los síntomas y signos del cansancio emocional (CE), con terapias médicas o psicológicas, para atacarlo en lo posible, desde la raíz (Calabrese, 2006).

Cuando ya se está en los inicios y se percibe la presencia de estos síntomas, se puede recurrir a muchas maneras de aliviarlo y hasta erradicarlo, y como primer paso se deben identificar las causas (Martinetti y Paladino,2005); para ello ese sugiere tomar medidas para aminorar los efectos del estrés diario, organizar mejor el tiempo y la jornada laboral, pero al mismo tiempo disponer de espacios de calidad para realizar actividades que sean del agrado y mejoren el estado de ánimo, reponer fuerzas y reemplazar la energía gastada, todo en franco equilibrio.

En correspondencia con lo anterior, ante la prevención y cuidados de la salud, se pueden presentar inconvenientes tales como, el desconocimiento, la negación y la no aceptación de que se está ante una situación de salud fuera de lo habitual; donde la principal dificultad según Calabrese (2006), es la resistencia del médico a admitir problemas y aceptar el título de paciente. Por lo cual, del autor antes mencionado se extrajeron ciertas ideas en 
relación a las medidas y recomendaciones que pueden ponerse en práctica al presentarse la sintomatología descrita:

- Disminuir los niveles de estrés por el trabajo, evitando factores estresantes; que serían muy particulares 0 individuales, puesto que por el tipo de personalidad, lo que resulta estresante para unos, puede no serlo para otros convirtiéndose más bien en retos y desafíos positivos.

- Someterse a revisión médica para la detección precoz, cuando se presuma y se sientan signos físicos, emocionales, mentales fuera de lo normal, en respuesta al estrés.

- Tratar de adaptarse a las exigencias propias del día a día, sin crearse expectativas irreales.

- En cuanto ya existen los signos, no negarse a esta nueva situación, y buscar asesoramiento psicológico, antes de que pueda verse comprometida la salud.

- Recurrir al apoyo de amigos y familiares, para descargar angustia, preocupaciones; evitando el aislamiento.

- Mucho se ha dicho sobre este aspecto: Equilibrar y priorizar entre la vida profesional y la vida familiar y personal; lo cual implica una toma de decisiones, oportuna y colocando énfasis en la salud y no en lo económico.

- Disfrutar de momentos de esparcimiento, recreación y descanso, tomando vacaciones cada cierto tiempo.

Al respecto, Tobie-Gutierrez y Nava-López (2012), aportan lo siguiente: "emplear técnicas de relajación, biofeedback, técnicas cognitivas (reestructuración cognitiva), resolución de problemas, entrenamiento de la asertividad, fomento de habilidades de afrontamiento y autocontrol de la conducta" (p. 236); estas son estrategias viables para tomar en cuenta en la prevención temprana del cansancio emocional, pero también para las etapas primeras etapas del síndrome, donde ya se haya tomado consciencia del problema y se tenga la convicción de que hay soluciones beneficiosas para evitar caer en crisis graves o extremas.

Saborío Morales y Hidalgo Murillo (2015), coinciden con Calabrese (2006), en algunos puntos, al referir que se debe prevenir la aparición de este síntoma con la utilización de algunas estrategias destinadas a modificar los sentimientos y pensamientos de las personas, algunas de ellas son: la adaptación de las expectativas personales a la realidad cotidiana; mantener el equilibrio entre áreas vitales: familia, amigos, aficiones, descanso, trabajo; fomentar una buena atmósfera de trabajo en espacios comunes, según objetivos comunes; limitar y organizar la agenda laboral; tratar de capacitarse, autoformarse, y complementar los conocimientos, dentro de la jornada laboral, sin ampliar o exceder las jornadas.

De cualquier forma, al estar en una posición, donde se tiene buena salud y no se han experimentado episodios que supongan estados de estrés, ansiedad y cansancio mental o físico, es más fácil poder prevenir su aparición. Cosa contraria sucede cuando ya el síntoma se ha instalado, en ese caso, la persistencia en el tiempo y el consiguiente agravamiento, tendría que diagnosticarse y aplicar el tratamiento respectivo, puesto que ya en esta fase los aspectos y signos que denotan el padecimiento del CE, que ha de estar en una fase grave o extrema, se ha presentado de forma insidiosa, no súbita, si no paulatina, cíclica, con el riesgo de repetirse a lo largo del tiempo, (Saborío Morales y Hidalgo Murillo, 2015).

\section{Anestesiólogos en época de pandemia por Covid-19}

La situación pandémica por COVID-19, ha llevado a los profesionales de la salud a enfrentarse a diversas situaciones, donde las jornadas laborales y las actividades habituales 
Cansancio emocional en médicos anestesiólogos, como factor asociado al síndrome de Burnout por el Covid-19

de su área, han tenido efectos variados y complejos. En el caso de los anestesiólogos, para los efectos de poder atender las demandas por pacientes contagiados en situación de salud crítica o grave, se han tenido que sumar a las acciones de los especialistas que están en primera línea de atención de la crisis, además de cumplir sus propias funciones como anestesiólogos.

Varias de las situaciones que enfrentan, tienen matices que llevan al extremo la rutina diaria de estos especialistas; las experiencias que se están viviendo en las $\mathrm{UCl}$ dan una muestra de lo que está sucediendo hoy en día con los anestesiólogos, por ejemplo, como lo resalta Monsalve (2020), en un reportaje recogido en El Espectador, donde el Dr. Rodrigo Morales, anestesiólogo colombiano, comenta una serie de situaciones que son su día a día: aumento de la carga laboral, ya que se triplicó; padecen de ansiedad y otras alteraciones de su salud mental; se están enfrentando a una grave crisis de desabastecimiento de medicamentos; por otro lado deben evitar el contacto familiar para no contagiarlos; tener que convivir en un ambiente laboral o profesional colapsado; ver como mueren sus colegas por contagio del virus Covid-19 y la incapacidad de otros por estar también contagiados, entre otros aspectos.

Al respecto, el Dr. Mauricio Vasco Ramírez presidente de la Sociedad Colombiana de Anestesiología, Reanimación, S.C.A.R.E, indica "trabajar en modalidades virtuales apoyados en telemedicina, y la necesidad de laborar en otras áreas de atención como el cuidado crítico; e incluso considerar la posibilidad de pasar al desempleo total", son algunas de las opciones y decisiones que se están tomando (Vasco Ramírez, 2020).

Enfrentar estas y otras situaciones son parte de la nueva normalidad ocupacional, de los anestesiólogos, en tal sentido, Calabrese (2020), señala:

"Entonces surge un nuevo concepto, el de nueva normalidad ocupacional para los anestesiólogos, este es un concepto dinámico que debe ser asumido como por parte de la comunidad de anestesiólogos, durante y luego de la pandemia del SARC-CoV-2COVID19; su dinámica sus recomendaciones, sus consecuencias y su interacción comunitaria en la sociedad" (p. 105).

El autor Cordero Escobar (2020, p.180), infiere que por las habilidades propias de su profesión, "el anestesiólogo es el médico más capacitado para el acceso a la vía respiratoria de los enfermos, vigila el antes, durante y después del acto quirúrgico". Por lo tanto es de entenderse que esté en contacto directo con cualquier infección; en esta pandemia del Covid19, "es uno de los especialistas que junto al intensivista y los cirujanos está directamente expuesto y en riesgo de contagio", (Cordero Escobar, 2020, p.180).

"Los anestesiólogos que atienden pacientes infectados por SARS-CoV-2/ Covid-19, tienen alto riesgo ocupacional durante la ejecución de una serie de procedimientos denominados: generadores de aerosoles (por inhalación de gotas) y los de transmisión por contacto (como el contacto con las membranas mucosas orales, nasales y oculares) desde un portador o desde superficies contaminadas con el virus" (Calabrese, 2020; p.105).

Aunque las relaciones, datos o estadísticos son pocos, se observa en la revista NEJM Catalyst Innovation in Care Delivery, un estudio que refiere como 242 personas encuestadas, están en contacto directo con el virus, entre los cuales se encuentran los anestesiólogos; donde también se reflejó que un $48 \%$ podrían contraerlo en el trabajo (Monsalve, 2020). Es 
preciso aclarar que las anteriores cifras estaban dadas para los primeros 7 meses del año 2020, actualmente ya entrado el 2021 ya deberían ser mucho más altas las cifras.

\section{La "nueva normalidad" y la salud emocional del anestesiólogo.}

El portal español, INFOSALUS (2021), resaltó la campaña que inició la Federación Mundial de Sociedades de Anestesiología (WSFA), en la cual se destaca la importancia del bienestar en salud del gremio de anestesiólogos a nivel mundial. Al respecto han creado el hashtag \#MyWellbeinglsYourWellbeing, que significa en español "mi bienestar es tu bienestar, la iniciativa fue apoyada por la Sociedad Española de Anestesiología, Reanimación y Terapéutica del Dolor (SEDAR).

El objetivo es que a nivel de todas las sociedades del mundo, se tome en cuenta la importancia del cuidado de la salud de los médicos anestesiólogos, tanto por parte de ellos mismos, como por parte de las asociaciones, su familia, colegas y compañeros de trabajo dentro de sus instituciones y comunidad en general; con lo cual es evidente que mientras más sano mental y físicamente estén estos profesionales médicos mayor será el beneficio y los resultados en el trato y seguridad de sus pacientes (INFOSALUS, 2021).

Por su parte, el Dr. Antonio Planas, (Secretario General de la Sociedad Española de Anestesiología, Reanimación y Terapéutica del Dolor; SEDAR), señala en una entrevista realizada para INFOSALUS (2021), que todos los seres humanos en especial, los anestesiólogos pueden estar sometidos a elevados niveles estrés durante el desarrollo de sus jornadas laborales además, queremos concienciar a los profesionales y dirigentes sobre la importancia de cuidar y respetar el bienestar laboral del personal sanitario".

A su vez, el Dr. Vasco Ramírez (2020), indicó en cuanto a la salud emocional de los médicos anestesiólogos, que la situación originada por la pandemia del Covid-19, los hace más propensos a sufrir trastornos emocionales y deterioro en su salud mental, al sentir impotencia o incertidumbre al ejercer sus funciones y correr riesgo de contagio para si mismo como para sus familiares cercanos, teniendo que enfrentarse a la disyuntiva de si cumplir sus funciones de asistencia sanitaria o buscar otra fuente de ingresos que no sea tan riesgosa. Razón por la cual, en algunas regiones o países han implementado atención psicológica para anestesiólogos (INFOSALUS, 2021).

A lo anterior se agrega, la importancia de transformar el habitual exceso de horas de trabajo, fatiga, productividad sin límite que conllevan al estrés laboral por trabajo con calidad, cuidando la salud y el bienestar ocupacional del anestesiólogo. Por ello es de vital importancia que se reconozcan los signos y síntomas que pueden estar afectando la salud emocional de los anestesiólogos, quienes debemos ser conscientes del momento histórico en el cual se está desarrollando su práctica profesional diaria.

Las actividades de los profesionales de la salud, especialmente de los anestesiólogos, están enmarcadas en una "nueva normalidad" como bien lo señalan algunos especialistas, que debe ser asumida con responsabilidad y cuidado; donde la observación de cambios y padecimientos tanto físicos como psicológicos, pueden ser una manifestación de un malestar emocional mayor, que requiere principalmente del reconocimiento, la aceptación y por ende de la identificación de los mismos; la falta de empatía, la fatiga, el cansancio excesivo, son signos que requiere de atención inmediata. 
Cansancio emocional en médicos anestesiólogos, como factor asociado al síndrome de Burnout por el Covid-19

\section{Conclusiones}

Las exigencias laborales generan en los individuos síntomas y estados de ánimo, que muchas veces no corresponden con las expectativas que se tienen de la profesión, con respecto a la satisfacción y calidad de vida que debería ofrecer. En el ámbito de los profesionales de la salud, especialmente de los anestesiólogos, las exigencias propias de la profesión revisten un nivel de estrés generado por la responsabilidad que esta acarrea: la presión asistencial, los marcos legales, las políticas institucionales, las largas jornadas laborales, el riesgo que implica para la propia salud del especialista, entre otras; a esto se le suma las exigencias del entorno relacionadas con el ambiente laboral, y otras de tipo personal.

La presión laboral en la profesión del anestesiólogo, si bien forma parte de su día a día, es una característica particular de la misma; cuando se presentan síntomas fuera de los parámetros normales, el individuo debe identificarlos y aceptar la situación a tiempo, para atacar y tratar precozmente. Esta es la manera más indicada de evitar males mayores, como lo es la aparición del cansancio emocional (CE); síntoma que cuando se instaura es clave en el padecimiento del síndrome de Burnout (SB) o estrés laboral.

Es así como conforme a los hallazgos obtenidos, se puede afirmar que el cansancio emocional constituye un factor clave para la prevalencia del síndrome de Burnout, que se manifiesta a través de la pérdida progresiva de la energía, el desgaste físico, mental, y cansancio; todo ello causado por la presencia continua de los mismos a través del tiempo, sin ser diagnosticados ni tratados eficientemente. Esta situación permite inferir que los anestesiólogos son uno de los gremios médicos que podría resultar más afectado con este síndrome, especialmente, en los actuales momentos de riesgo sanitario producto del Covid-19, donde los sentimientos de tensión, preocupación, miedo e incertidumbre aumentan dadas las condiciones y contacto cercano al que están sometidos con personas diagnosticadas con el virus.

Por lo cual, en las últimas décadas, las asociaciones y sociedades gremiales, han tomado medidas preventivas que incluyen principalmente la concientización por parte de los propios especialistas, del cuidado de su salud, física pero emocional y mental también, en beneficio de sí mismos pero también, para la seguridad de los pacientes.

Por consiguiente, para palear o aliviar las tensiones emocionales propias del ejercicio profesional del anestesiólogo, como el estrés característico de esta, o situaciones más graves que comprometan la salud emocional de los anestesiólogos, como el cansancio emocional proclive a un Burnout; se recomiendan fomentar la aplicación de medidas o estrategias alternativas que ayuden efectivamente a lograr minimizar las tensiones propias de su labor y las generadas por la incertidumbre y riesgo de contagio ante la presencia del Covid-19.

Para finalizar, es imperativo que en una época tan complicada como la actual, donde se ha presentado el imprevisto e inconveniente más grave de salud pública, que hayamos podido experimentar las actuales generaciones, como lo es la pandemia del Covid-19, que se realicen los esfuerzos necesarios de parte de todas las instituciones responsables e involucradas, (gubernamentales y privadas), para solventar las delicadas situaciones en cuanto a salubridad y seguridad en salud que se han surgido y seguirán surgiendo a medida que pasa el tiempo, afectando directamente al personal de salud, entre los cuales se encuentran los médicos anestesiólogos 
Se debe realizar todo el esfuerzo posible, humano e institucional y tomar las medidas necesarias, para no dejar a la deriva las exigencias que les corresponde cumplir, para la protección integral de los trabajadores en general, pero aún más a los profesionales de la anestesiología, quienes se enfrentan directamente con esta difícil situación, viendo muchas veces mermados sus esfuerzos, y contribución por medio de sus actuaciones profesionales, sin recibir la atención, ni apoyo suficientes, para poder continuar dignamente desarrollando su labor, exponiéndose al Covid-19 entre otros riesgos dentro de los centros clínicos donde se desempeñan.

\section{Referencias Bibliográficas}

Arayago Iriarte, Robelsy; González Villacieros, Álvaro; Limongi Sterse, María y Guevara Rivas, Harold. (2016). Síndrome de Burnout en residentes y especialistas de anestesiología. Revista Salus. 20 (1), Venezuela. (Pp: 13-21). Extraído de: https://www.redalyc.org/articulo.oa?id=375946213004

Calabrese, Gustavo. (2006). Impacto del estrés laboral en el anestesiólogo. Investigación en salud. Colombian Journal of Anestesiology, 34 (4), Bogotá. (Pp: .233-240.) Extraído de: $\quad$ http://www.scielo.org.co/scielo.php?script=sci_arttext\&pid=S0120$\underline{33472006000400003}$

Calabrese, Gustavo, (2020). La nueva normalidad ocupacional para los anestesistas: más allá de la pandemia SARS-CoV-2 COVID-19. Revista Colombiana de Anestesiología. 48 (3), Colombia. (Pp: 105-106) Extraído de: https://www.revcolanest.com.co/index.php/rca/article/view/895/1374

Castillo Ramírez, Sisy. (2000). El síndrome de "Burn Out" o síndrome de agotamiento profesional. Revista Medicina Legal, 17 (2), Costa Rica. (Pp:). Extraído de: https://www.scielo.sa.cr/scielo.php?script=sci_arttext\&pid=\$1409-00152001000100004

Clínica Galatea (2018). Burn Out o síndrome de desgaste en profesionales de la salud. Extraído de: https://www.clinica-galatea.com/es/bloc/burn-out-sindrome-desgaste/

Cordero Escobar, Idoris, (2020). Papel del anestesiólogo en la pandemia de COVID-19. Revista Mexicana de Anestesiología, 43 (3), Cuba (Pp: 180-181). Extraído de: https://www.medigraphic.com/pdfs/rma/cma-2020/cma203b.pdf https://dx.doi.org/10.35366/93318

González Ramírez, Mónica y Landero Hernández, René. (2007). Factor Structure of the Perceived Stress Scale (PSS) in a Sample from Mexico. The Spanish Journal of Psychology, $10 \quad(1), \quad$ España. (Pp: 199-206). Extraído de: https://www.redalyc.org/pdf/172/17210120.pdf

INFOSALUS. (2021). Anestesiólogos de todo el mundo promueven una campaña para recordar la importancia de su bienestar laboral. Infosalus. Asistencia. Extraído de: https://www.infosalus.com/asistencia/noticia-anestesiologos-todo-mundo-promuevencampana-recordar-importancia-bienestar-laboral-20201015121057.html

Lledó Carreres, Asunción; Perandones González, Teresa; Herrera Torres, Lucía; Lorenzo Lledó, Gonzalo. (2014). Cansancio emocional, autoestima y satisfacción con los estudios en estudiantes universitarios. International Journal of Developmental and Educational Psychology, 7 (1), España. (Pp: 161-170). DOI: https://doi.org/10.17060/ijodaep.2014.n1.v7.787 
Cansancio emocional en médicos anestesiólogos, como factor asociado al síndrome de Burnout por el Covid-19

Maslach, Chistina y Jackson, Susan. (1982). Burnout in health professions: A social psychological analysis. En Sanders, GLenn y Suls, Jerry. Social psychology of health and illness. Lawrence Erlbaum Associates. USA.

Martinetti, Héctor y Paladino, Miguel (2005). La salud del anestesiólogo (segunda parte). Las agresiones psicosociales. Revista Argentina de Anestesiología, 63, (2), Argentina (Pp:115-127). Extraído de: https://www.anestesia.org.ar/search/articulos completos/1/1/886/c.pdf

Martínez Pérez, Anabella, (2010). El síndrome de Burnout. Evolución conceptual y estado actual de la cuestión. Vivat Academia, XIII (112), España. (Pp: 42-80). DOI: https://doi.org/10.15178/va.2010.112.42-80

Monsalve, Mónica. (2020). Anestesiólogos agotados por la pandemia. El espectador. Salud. Extraído de: https://www.elespectador.com/noticias/salud/anestesiologos-agotados-porla-pandemia/?outputType=amp

Organización Mundial de la Salud (OMS, 2004). Salud mental en el lugar de trabajo. Extraído de: https://www.who.int/mental_health/in the workplace/es/

Parra Contreras, Reyber. (2020). Una perspectiva del mundo que se nos avecina. Revista de la Universidad del Zulia. 3aépoca. 11 (29), Venezuela. (Pp: 3-5). DOI: https://doi.org/10.46925/rdluz.29.01

Rodríguez Paipilla, Magda; Rodríguez Gómez, Rodolfo; Riveros Gutiérrez, Arnold; Rodríguez D’Luyz, María; Pinzón Salamanca, Javier. (2011). Síndrome de Burnout y factores asociados en personal de salud en tres instituciones de Bogotá en diciembre de 2010. Tesis de especialista. Especialización en epidemiología. Universidad del Rosario. Colombia.

Saborío Morales, Lachiner y Hidalgo Murillo, Luis. (2015). Síndrome de Burnout. Medicina legal, 32 (1), Costa Rica. (Pp: 1-6). Extraído de: https://www.scielo.sa.cr/scielo.php?script=sci_arttext\&pid=\$1409-00152015000100014 Sacrístan, José y Millán, Jesús. (2020). El médico frente a la COVID-19: lecciones de una pandemia. Revista Educación Médica. 21 (4), España. (Pp: 265-271). DOI: https://doi.org/10.1016/i.edumed.2020.06.002

Solís-Condor, Risof; Tantalean del Aguila, Martín; Burgos-Aliaga, Rosa; y Chambi Torres, Javier. (2017). Agotamiento profesional: prevalencia y factores asociados en médicos y enfermeras en siete regiones del Perú. Anales de la facultad de Medicina, 78(3), Perú. (Pp: 270-276). DOI: http://dx.doi.org/10.15381/anales.v78i3.13757

Secín Diep, Ricardo; y Rodríguez Weber, Federico; (2016). Síndrome de desgaste en médicos residentes de un hospital privado. Artículo original, Medicina Interna México, 32 (1), Mexico. (Pp: 33-40). Extraído de: https://www.medigraphic.com/cgibin/new/resumen.cgi?IDARTICULO $=64339$

Tobie-Gutierrez, Wendy y Nava-López, Jorge, (2012). Burnout, su impacto en la residencia médica y en la atención de los pacientes. Revista Mexicana de Anestesiología. 35 (1), Mexico. (Pp: 233-237). Extraído de: https://www.medigraphic.com/pdfs/rma/cma2012/cmas121g2.pdf

Torres Montes de Oca, Amy; Puente Téllez, Hugo y Ramírez López, Beatriz (2020). Desafíos para el anestesiólogo en pacientes con Covid-19. Revista cubana de anestesiología 

Vol. 23 (2): 450-465. Mayo-Agosto 2021

y reanimación, 19 (2), Cuba. Extraído de: http://www.revanestesia.sld.cu/index.php/anestRean/article/view/654/915\#text-sec3

Vasco Ramírez, Mauricio. (2020). ¿Estamos preparados los anestesiólogos para el "nuevo normal"?. Revista Colombiana de Anestesiología, 48, (4), Colombia. (Pp: 1-3). DOI: https://doi.org/10.5554/22562087.e921

Zelaya Hurtado Fiorella Leslye (2016). Relación entre Nivel de Estrés y Carga Laboral en Profesionales de Enfermería Hospital Caraz 2016. Tesis para licenciatura. Escuela profesional de Enfermería. Universidad San Pedro. Perú. 